\title{
IS POPULATION'S CARDIORESPIRATORY FITNESS REALLY DECLINING?
}

\author{
Markéta Sovová1, Eliška Sovová1, Amjad Ghazal Asswad², Milan Sova ${ }^{3}$ \\ ${ }^{1}$ Department of Sports Medicine and Cardiovascular Rehabilitation, Palacký University Olomouc, Olomouc, Czech Republic \\ ${ }^{2}$ Emergency Department, West Middlesex University Hospital, London, United Kingdom of Great Britain and Northern Ireland \\ ${ }^{3}$ Department of Respiratory Medicine, Faculty of Medicine and Dentistry, Palacký University Olomouc, Olomouc, Czech Republic
}

\begin{abstract}
SUMMARY
Objective: Cardiorespiratory fitness (CRF) is defined as the capacity of the cardiovascular and pulmonary systems to meet the oxygen demands of the body during physical work. Poor CRF is connected with a higher risk for the development of various noninfectious diseases such as cardiovascular disease or malignancies. The standard test for the assessment of CRF is exercise testing with the measurement of maximal oxygen consumption ( $\mathrm{VO}_{2}$ max). Standard $\mathrm{VO}_{2}$ max values for adult men and women in the Czech Republic have been available since the 1970 s without being updated. According to experts, these standard values are now unusable for contemporary CRF measurements of the population in the Czech Republic. The Fitness Registry and the Importance of Exercise: a National Database (FRIEND) - 4,494 patients (1,717 men) defined new standard values for bicycle ergometry CRF for the population in the United States of America. The aim of the study was the statistical comparison of $\mathrm{VO}_{2}$ max values (reference standards) in the 1970s population in the Czech Republic with the new reference standards of the FRIEND registry.

Methods: All analyses were performed using IBM SPSS statistics and all tests with a p-value of less than 0.05 were considered statistically significant.

Results: $\mathrm{VO}_{2}$ max norms for women in the Czech population were higher in all age categories with statistically significant differences in the categories $30-39,40-49$ and $50-59$ ( $p<0.001)$. In the male population aged $20-29$ years, $\mathrm{VO}_{2}$ max was significantly higher in the FRIEND registry $(p<0.001)$ in contrast to the other age categories, 30-39, 40-49 and 50-59, which were significantly higher in the Czech population ( $p<0.001)$.

Conclusions: Czech $\mathrm{VO}_{2}$ max population norms from the 1970s are (with the exception of age category 20-29 years) higher than values from the recent FRIEND registry.
\end{abstract}

Key words: cardiorespiratory fitness, Czech population, reference standards, maximal oxygen consumption

Address for correspondence: M. Sova, Department of Respiratory Medicine, University Hospital Olomouc, I. P. Pavlova 6, Olomouc, Czech Republic. E-mail: milan.sova@email.cz

https://doi.org/10.21101/cejph.a5912

\section{INTRODUCTION}

Cardiorespiratory fitness (CRF) is defined as the capacity of the cardiovascular and pulmonary systems to meet the oxygen demands of the body during physical work. Poor CRF is connected with a higher risk for the development of various noncommunicable diseases such as cardiovascular disease or cancers and with an increase in mortality rate $(1,2)$. CRF provides information related to functional capacity and exercise prescription (3). An increase in CRF is connected with a decrease in mortality rate (4). The American Heart Association published an article on the importance of CRF assessment (5) as the addition of CRF to the traditional risk factors of cardiovascular disease improves the reclassification of risk for adverse outcomes. CRF is potentially a stronger predictor of mortality than established risk factors such as smoking, hypertension, high cholesterol and type 2 diabetes mellitus.

The standard test for the assessment of CRF is exercise testing with the measurement of $\mathrm{VO}_{2}$ max or estimating $\mathrm{VO}_{2}$ max from the peak work rate by using a regression formula. This metabolic demand for a given work rate is conventionally expressed in metabolic equivalents (METs). One MET is considered to be equivalent to the amount of oxygen consumed at rest $(3.5 \mathrm{ml}$ $\mathrm{O}_{2} / \mathrm{kg} / \mathrm{min}$ ). Numerous recent studies reveal, that each $1-\mathrm{MET}$ higher CRF was associated with a $10-25 \%$ improvement in survival (5).

In the Czech Republic, $\mathrm{VO}_{2}$ max norms have been available since the $1970 \mathrm{~s}(6,7)$. These norms are based on a multicentre study using a bicycle spiroergometer. The study sample was recruited randomly from the general population. These same norms from the 1970 s are still used in current clinical practice. Whether or not these norms should be re-evaluated due to changes in population habits is now under discussion, with many experts being of the opinion that these norms are no longer a true reflection of the CRF of the Czech population.

The Fitness Registry and the Importance of Exercise: a National Database (FRIEND) is a multi-institutional initiative established in 2014 with the primary objective of establishing normative CRF values for the population of the United States across the adult lifespan (8). There were 10 participating centres, where participants completed a graded exercise test with direct measurement of $\mathrm{VO}_{2}$ max. All laboratories used valid calibration 
and testing procedures with experienced personnel. The inclusion criteria included age $\geq 20$ years and absence of cardiovascular disease or chronic obstructive pulmonary disease. Maximal effort was determined by a peak respiratory exchange ratio (RER) $\geq 1.1$.

The FRIEND registry (4,494 subjects, 1,717 men) defined new CRF population norms for the USA population (9). These are the first norm values for bicycle ergometry as previous studies were performed using a treadmill test.

Authors of the FRIEND registry declare that there are not available much population norms worldwide for comparison without any mention about existing Czech norms. The aim of this analysis is to compare current American and older Czech norms and to test the hypothesis that CRF is declining in the general population.

\section{MATERIALS AND METHODS}

This study is based on a statistical comparison of Czech $\mathrm{VO}_{2}$ max population norms (from the 1970s) $(6,7)$ and current data from the FRIEND registry (9).

Both these are based on multicentric trials ( 8 centres in Czechoslovakia (CS) and 10 centres in the USA). In CS a unified protocol was used $-3 \times 6$ minute periods of increasing, submaximal workload followed by a ramp test $(15 \mathrm{~W} /$ minute). In the USA, the protocols used varied between centres. Oxygen consumption was measured using the available methods of the time (Douglas bags; mixing chamber for breath by breath analysis). Maximal work was defined in CS as maximal heart rate and subject exhaustion whereas in the USA as a RER $>1$.1. Available statistical methods were used in both studies and normal values were presented as a mean and standard deviation.

Our analyses were carried out using the software IBM SPSS, Student's t-test with all tests with a p-value of less than 0.05 being considered as statistically significant.

\section{RESULTS}

$\mathrm{VO}_{2}$ max in different age categories and the statistical comparison is presented in Table 1 (females) and Table 2 (males) and in Figures 1, 2.

Population norms for women of all age categories are higher in the Czech population. In the age groups 30-39, 40-49 and $50-59$ these differences are statistically significant $(\mathrm{p}<0.001)$.

Similarly, in male population in the age groups 30-39, 40-49 and $50-59, \mathrm{VO}_{2}$ max norms were significantly higher in the Czech population $(p<0.001)$. The only category in which a significantly higher $\mathrm{VO}_{2}$ max was found in the FRIEND registry population was in the age group 20-29 $(\mathrm{p}<0.001)$.

\section{DISCUSSION}

In this comparison, it has been found that the Czech population norms from the 1970s are higher than the current values from the FRIEND registry. Only in one category (20-29) was there an exception to this. From this data, it is possible to conclude that the FRIEND registry population has lower CRF in comparison with the 1970s Czech population. Higher results found in the 20-29-year-old male category could be partially explained by possible population differences with the inclusion of more athletes.

The results of the FRIEND registry were compared in the original paper (9) with the results of the study by Grigaliuniene et al. (10) a pilot study performed on 160 healthy Lithuanians. With the obvious limitation being the small sample size, when comparing woman of the Lithuanian and Czech populations, only in the age category 20-29 were the Lithuanian norms higher than in their Czech counterparts. Lithuanian male norms were higher in the following age categories: 20-29 and 30-39.

Paap and Takken (11), and Takken et al. (12) published two systematic reviews in 2014 and 2019, where they studied refer-

Table 1. $\mathrm{VO}_{2}$ max in females

\begin{tabular}{|l|c|c|c|c|c|}
\hline Age (years) & $\begin{array}{c}\text { USA } \\
\text { mean (SD) }\end{array}$ & $\mathbf{n}$ & $\begin{array}{c}\text { CZ 1970s } \\
\text { mean (SD) }\end{array}$ & $\mathrm{n}$ & $\mathrm{p}$-value \\
\hline $20-29$ & $30.8(9.4)$ & 235 & $32.0(5.0)$ & 222 & 0.092 \\
\hline $30-39$ & $22.2(6.2)$ & 282 & $29.4(4.6)$ & 188 & $<0.001$ \\
\hline $40-49$ & $20.1(5.1)$ & 562 & $27.7(4.4)$ & 133 & $<0.001$ \\
\hline $50-59$ & $18.0(4.1)$ & 876 & $25.2(3.8)$ & 34 & $<0.001$ \\
\hline
\end{tabular}

USA - United States of America; CZ - Czech Republic, former Czechoslovakia

Table 2. $\mathrm{VO}_{2}$ max in males

\begin{tabular}{|l|c|c|c|c|c|}
\hline Age (years) & $\begin{array}{c}\text { USA } \\
\text { mean (SD) }\end{array}$ & $\mathbf{n}$ & $\begin{array}{c}\text { CZ 1970s } \\
\text { mean (SD) }\end{array}$ & $\mathbf{n}$ & p-value \\
\hline $20-29$ & $42.0(10.5)$ & 191 & $39.0(6.4)$ & 320 & $<0.001$ \\
\hline $30-39$ & $30.8(7.8)$ & 182 & $36.0(7.0)$ & 368 & $<0.001$ \\
\hline $40-49$ & $28.0(6.7)$ & 373 & $35.3(6.0)$ & 300 & $<0.001$ \\
\hline $50-59$ & $26.1(6.2)$ & 475 & $32.7(4.7)$ & 102 & $<0.001$ \\
\hline
\end{tabular}

USA - United States of America; CZ - Czech Republic, former Czechoslovakia 


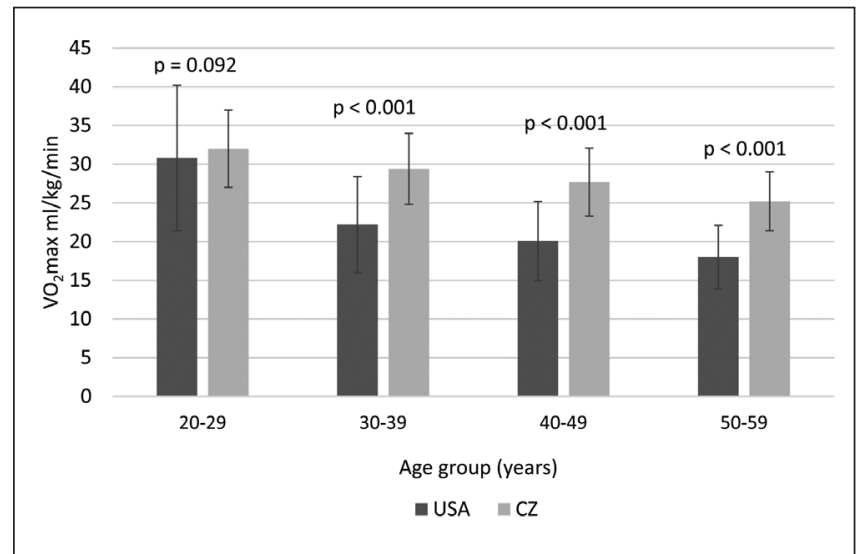

Fig. 1. $\mathrm{VO}_{2}$ max in females.

USA - United States of America; CZ - Czech Republic, former Czechoslovakia; data is presented as mean $\pm S D$; the difference between populations was tested using Student's t-test

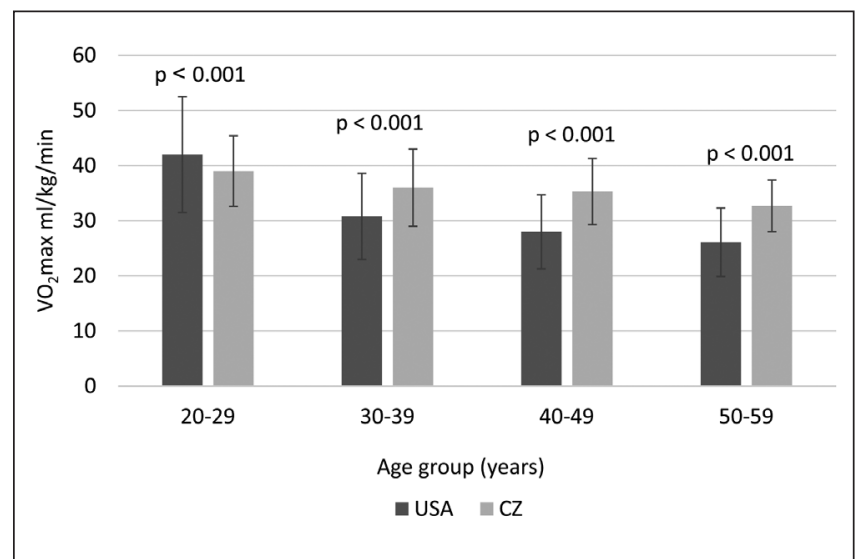

Fig. 2. $\mathrm{VO}_{2}$ max in males.

USA - United States of America; CZ - Czech Republic, former Czechoslovakia; data is presented as mean $\pm S D$; the difference between populations was tested using Student's t-test

ence values in healthy adults in literature. In the first review they selected 35 studies $(25,826$ subjects) with cardiopulmonary exercise testing (CPET) reference values published in the years 1980-2014, 22 were performed using bicycle ergometry, 12 using treadmill (where 1 study had used both). The results on treadmill and bicycle ergometers are not directly comparable as cardiorespiratory fitness is routinely $7-18 \%$ higher running compared to cycling. In the second review 29 studies with published CPET reference values were selected (87,256 subjects), 14 were performed using bicycle ergometry, 14 using treadmill (1 using both). In both reviews no single set of ideal reference values was found. Authors concluded that harmonization of CPET data is still urgently needed and recommend FRIEND as an excellent source for CPET reference values.

These systematic reviews did not deal with identifying reference values however just discussed that reference values may change over time and thus should be regularly updated and validated. There is a clearly defined need to produce a database of reference values which should also include longitudinal data.

The biggest studies (more than 1,000 participants) using bicycle ergometry included in the systematic review were performed in the USA by Kaminsky et al. (9), in Belgium by Buys et al. (13), in the Netherlands by Mylius et al. (14) and Van de Poppe et al. (15).
Buys et al. (13) published results of the oxygen uptake efficiency slopes of 1,411 healthy 20-60-year olds from the UPLIFT study (friends, family, and colleagues). This parameter is calculated from a part of the test, so it is not possible to compare it with FRIEND or Czech norms.

Mylius et al. (14) published reference values for the Dutch population. As a retrospective study of CPET using bicycle ergometry results from 4,477 subjects from 11 healthcare centres were studied, gas exchange analysis was done by bag collection, mixing chamber for breath by breath analysis. The subjects included underwent CPET for numerous reasons including work, sport related checks, scientific studies or personal motivation. The results of $\mathrm{VO}_{2}$ peak are given in $\mathrm{ml} / \mathrm{min}$, which cannot be compared with Czech norms. The same register is used in the Van de Poppe et al. study (15) where a new formula to calculate peak work rate is determined from a smaller group.

Rapp et al. (16) in 2018 published reference values for the adult population of Germany. The limitation of this study is inclusion of volunteers from preventive programmes who were mainly "white collar" workers. This population differs significantly from the general German population in the prevalence of smoking and obesity. Thus, it is not surprising that $\mathrm{VO}_{2} \max$ in this population was significantly higher than $\mathrm{VO}_{2}$ max observed in the FRIEND registry.

In 2016 a big study DANHES (17) was published, in which a random sample of Danish adults was invited to participate. However, in this study, cardiorespiratory fitness was estimated indirectly from a prediction model and thus only $49 \%$ of participants reached their age predicted maximal heart rate.

Even though there is a gap of almost 40 years between the publication of Czech norms and the FRIEND registry, it is possible to perform statistical comparisons as according to manufacturers the results are comparable. Czech norms assessed the general population and FRIEND selected subjects in which we would expect a better approach towards healthy lifestyle as was published by Rapp et al. (16). These results, in line with our hypothesis, suggest that CRF is decreasing.

In the literature available there are some studies concerning the development of physical fitness. For example, Tomkinson et al. (18) analysed 55 studies of treadmill tests in children and adolescents in 11 countries in the period between 1980-2000. A decline in physical fitness was shown here in all groups $(0.43 \%$ per year with the decline being more pronounced in older groups). Ekblom-Bak et al. (19) recently published a pronounced decline in mean cardiorespiratory fitness between 1995 and 2017 in Swedish adults (a decrease of 6.7\% in absolute $\mathrm{VO}_{2}$ max), with the proportion of individuals with low CRF having almost doubled.

On the other hand, some studies are not in support of this phenomenon. Studies AVENA and HELENA (20) found an increase in CRF between 2001-2002 and 2006-2007, respectively, in both genders.

Cardiorespiratory fitness decline is caused by several factors. One of the most important being the individual's level of physical activity (17). In the Czech registry there was a high proportion of recreational athletes, e.g. of the 368 subjects aged 35, 283 were physically active. This data is not known for the FRIEND registry. This could be the cause of difference in the CRF levels observed in these two cohorts. 
It has been discussed whether it is necessary to perform a similar study to that of the FRIEND registry to obtain new population norms for the Czech Republic. An alternative option would be to work on the improvement of the level of physical activity of the general population to reach similar CRF levels as were observed almost 50 years ago. This would probably also concomitantly reduce the risk of cardiovascular disease and further reduce cardiovascular morbidity and mortality.

\section{CONCLUSION}

Population norms for maximal oxygen consumption derived from the Czech population in the 1970s are higher than those in the recent FRIEND registry

\section{Author's Contribution}

MaS, ES and MS designed this study, searched the literature and wrote this manuscript; AGA collected data and performed language correction.

\section{Conflict of Interests}

None declared

\section{REFERENCES}

1. Kodama S, Saito K, Tanaka S, Maki M, Yachi Y, Asumi M, et al. Cardiorespiratory fitness as a quantitative predictor of all-cause mortality and cardiovascular events in healthy men and women: a meta-analysis. Jama. 2009;301(19):2024-35.

2. Schmid D, Leitzmann MF. Cardiorespiratory fitness as predictor of cancer mortality: a systematic review and meta-analysis. Ann Oncol. $2015 ; 26(2): 272-8$.

3. American College of Sports Medicine. ACSM's guidelines for exercise testing and prescription. Tenth edition. Philadelphia: Wolters Kluwer; 2018 .

4. Lee DC, Artero EG, Sui X, Blair SN. Mortality trends in the general population: the importance of cardiorespiratory fitness. J Psychopharmacol. 2010;24(4 Suppl):27-35.

5. Ross R, Blair SN, Arena R, Church TS, Després JP, Franklin BA, et al. Importance of Assessing Cardiorespiratory Fitness in Clinical Practice: A Case for Fitness as a Clinical Vital Sign: A Scientific Statement From the American Heart Association. Circulation. 2016;134(24):e653-99.

6. Máček M, Seliger V, Vavra J, Škranc O, Horák J, Pirič M, Handzo P, Rouš J, Jirka Z. Physical fitness of the Czechoslovak population between the ages of 12 and 55 years. Oxygen consumption and pulse oxygen. Physiol Bohemoslov. 1979;28(1):75-82.

7. Seliger V, Bartunek Z. Mean values of various indices of physical fitness in the investigation of Czechoslovak population aged $12-55$ years. Prague: ČSTV; 1976.
8. Kaminsky LA, Arena R, Beckie TM, Brubaker PH, Church TS, Forman $\mathrm{DE}$, et al. The importance of cardiorespiratory fitness in the United States: the need for a national registry: a policy statement from the American Heart Association. Circulation. 2013;127(5):652-62.

9. Kaminsky LA, Imboden MT, Arena R, Myers J. Reference standards for cardiorespiratory fitness measured with cardiopulmonary exercise testing using cycle ergometry: data from the Fitness Registry and the Importance of Exercise National Database (FRIEND) registry. Mayo Clin Proc. 2017;92(2):228-33.

10. Grigaliuniene A, Ramonas A, Celutkiene J, Sileikiene V, Rudys A, Juocevicius A, et al. Cardiorespiratory parameters of exercise capacity in a healthy Lithuanian population: the pilot study. Hellenic J Cardiol. 2013;54(2):107-18.

11. Paap D, Takken T. Reference values for cardiopulmonary exercise testing in healthy adults: a systematic review. Expert Rev Cardiovasc Ther. 2014;12(12):1439-53.

12. Takken T, Mylius CF, Paap D, Broeders W, Hulzebos HJ, Van Brussel M, et al. Reference values for cardiopulmonary exercise testing in healthy subjects - an updated systematic review. Expert Rev Cardiovasc Ther. 2019;17(6):413-26.

13. Buys R, Coeckelberghs E, Vanhees L, Cornelissen VA. The oxygen uptake efficiency slope in 1411 Caucasian healthy men and women aged 20-60 years: reference values. Eur J Prev Cardiol. 2015;22(3):356-63.

14. Mylius CF, Krijnen WP, van der Schans CP, Takken T. Peak oxygen uptake reference values for cycle ergometry for the healthy Dutch population: data from the LowLands Fitness Registry. ERJ Open Res. 2019;5:000562018. doi: 10.1183/23120541.00056-2018.

15. Van de Poppe DJ, Hulzebos E, Takken T. Reference values for maximum work rate in apparently healthy Dutch/Flemish adults: data from the LowLands fitness registry. Acta Cardiol. 2019;74(3):223-30.

16. Rapp D, Scharhag J, Wagenpfeil S, Scholl J. Reference values for peak oxygen uptake: cross-sectional analysis of cycle ergometry-based cardiopulmonary exercise tests of 10090 adult German volunteers from the Prevention First Registry. BMJ Open. 2018;8(3):e018697. doi: 10.1136/ bmjopen-2017-018697.

17. Eriksen L, Grønbaek M, Helge JW, Tolstrup JS. Cardiorespiratory fitness in 16025 adults aged 18-91 years and associations with physical activity and sitting time. Scand J Med Sci Sports. 2016;26(12):1435-43.

18. Tomkinson GR, Leger LA, Olds TS, Cazorla G. Secular trends in the performance of children and adolescents (1980-2000): an analysis of 55 studies of the $20 \mathrm{~m}$ shuttle run test in 11 countries. Sports Med. 2003;33(4):285-300.

19. Ekblom-Bak E, Ekblom Ö, Andersson G, Wallin P, Söderling J, Hemmingsson E, et al. Decline in cardiorespiratory fitness in the Swedish working force between 1995 and 2017. Scand J Med Sci Sports. 2019 Feb;29(2):232-9.

20. Moliner-Urdiales D, Ruiz JR, Ortega FB, Jiménez-Pavón D, VicenteRodriguez G, Rey-López JP, et al. Secular trends in health-related physical fitness in Spanish adolescents: the AVENA and HELENA studies. J Sci Med Sport. 2010;13(6):584-8. 